\title{
Best Practices Guidelines for Publishing in the Bioethics Literature
}

Following are best practices guidelines for publishing in the bioethics literature as complied by editors from the American Journal of Bioethics, Bioethics, Cambridge Quarterly of Healthcare Ethics, Developing World Bioethics, Kennedy Institute of Ethics Journal, Nursing Ethics, and Theoretical Medicine as part of the Journal Editors Project, sponsored by the Greenwall Foundation. In response to authors' continuing requests for information covered by the guidelines, $C Q$ makes them regularly available for easy reference.

\section{Guidelines}

Transparency

1) Authors must declare to the journal any interests they believe would materially affect a reasonable reader's judgment about the validity of the authors' claims.

2) Such declarations will normally be published by the journal with the article when it appears in either electronic or paper form.

3) Authors must declare to the journal any external funding sources supporting the work that produced the article and must state the source(s) in an acknowledgements section of the article.

\section{Authorship}

1. For original empirical research papers or review articles regarding empirical research, the journal asks authors to adhere to the authorship criteria of the International Committee of Medical Journal Editors.

2. For philosophical, theological, policy, historical, legal, and other theoretical types of articles, criteria for authorship will be based on the general standards of the humanistic disciplines. Specifically, those who claim authorship should

a. Thoroughly understand the argument of the article

b. Agree with the argument and its conclusions at least at the level of a consensus among the authors

c. Have been substantially involved in the writing of the article, generally understood to include at least two of the following:

i. Generating the idea for the article

ii. Outlining the argument

iii. Supplying the abstract

iv. Actually writing parts of the article's text

v. Substantially critiquing and editing drafts

3. The following are considered insufficient in themselves as criteria for authorship:

a. Mentoring of a student or junior colleague who writes the article

b. Reading and commenting on a draft of an article conceived and written by someone else 
c. Obtaining funding to support the work

d. Functioning as the head of the academic unit in which the work was produced

\section{Plagiarism}

Copying text directly from the work of other authors without setting it out as quotations and without providing appropriate referencing constitutes plagiarism.

The journals will generally follow the COPE guidelines concerning the handling of plagiarism. This entails inter alia that if a submitted manuscript contains clear plagiarism (i.e., unattributed use of large portions of text and/or data, presented as if they were by the author), the journal will contact the author, requiring an explanation, and if no satisfactory explanation is given, the journal may contact the author's institution or other body responsible for research governance.

\section{Redundant Publication}

Publishing work that is identical to, or has major overlap with, previous work by the same author(s) constitutes redundant publication.

In all cases involving the submission of a manuscript that could be seen as redundant publication, the corresponding author should alert the journal in question to this fact. If this is not done, the journals will in general follow the COPE guidelines concerning the handling of redundant publication. This entails inter alia that the journal will contact the author, requiring an explanation, and if no satisfactory explanation is given, the journal may contact the author's institution or other body responsible for research governance.

In the case of empirical research, redundant or duplicate publication should in general be avoided.

In the case of philosophical/analytic research, redundant (but not duplicate) publication may be warranted in situations in which the nonredundant part of the manuscript contains significant, new, original argument or material. The journal will decide whether this is the case and may reject an article containing major overlap with previous work purely on this ground.

\section{Confidentiality}

In case studies, the privacy of patients should be respected. Cases should be written so as to disguise identifiers. The permission of any participants who are likely to be identifiable from the details of the case description should be obtained, unless this presents a practical impossibility.

In cases that have attained public notoriety, bioethical discussion should be confined to the facts publicly known.

\section{Scholarship}

A scholarly article in bioethics should

1) Situate the context of the topic and argument within the context of philosophical ethics, theological ethics, and the theories and subject matter of bioethics 
2) Acknowledge previous literature about the topic under discussion

3) Manifest conceptual clarity in definitions and distinctions

4) Report facts accurately and with appropriate references

5) Demonstrate skill in developing logical arguments and analyzing counterarguments

6) Be written clearly and articulately

Research Involving Human Subjects

It is a necessary but not sufficient condition for the publication of articles presenting research involving human subjects that the research described is conducted in accordance with the relevant international and national standards and regulations governing research involving human subjects. At the time of submission, the authors must state whether and how the research complies with this condition.

\section{Social Responsibility}

Institutions or groups involved in the production of bioethics publications have a social responsibility to make every effort to ensure that people in developing countries* have realistic access to the content of their publications (on request), including the availability of printed materials at shipping cost. 


\section{Cambridge Quarterly of Healthcare Ethics}

\section{GUIDELINES FOR CONTRIBUTORS}

SCOPE OF THE JOURNAL. Cambridge Quarterly of Healthcare Ethics is designed to serve as an international forum for addressing the increasingly complex challenges of biology, medicine, and healthcare. As a journal committed to expanding the community of bioethicists worldwide, CQ welcomes well-argued papers from a variety of methodological and normative viewpoints.

PREPARATION OF MANUSCRIPTS. Papers submitted to CQ should be sent as electronic copy, preferably in MS Word, and should contain in the following order: title page, text, references. Manuscripts typically should not exceed 3,500 words, including endnotes. On a separate page, supply a brief entry listing academic degrees, institutional affiliation, and current projects for a "Contributors" section that appears in each issue of CQ. More detailed guidelines follow.

Title Page: Title of the article, name of each author with institutional affiliation and complete mailing address for correspondence, plus phone and fax numbers and e-mail address. Include a short title of 45 characters or fewer to be used as a runninghead. Acknowledgments, if any, are to be provided with the submission as an unnumbered footnote. They are not to be added later with proof corrections.

References: Responsibility for accuracy and thoroughness of citations rests with the author(s). References are to be placed as endnotes following the article (not as footnotes on each page) and are to be numbered in the order of the callouts. For multiple callouts of the same reference, each callout is to be given its own superscript arabic number; then in the Notes section a crossreference should be used, styled as in item 4 below. The names of the first six authors of each reference item should be provided, followed by ", et al." if there are more than six authors.

References should follow the format of the International Committee of Medical Journal Editors, with the CQ modification that titles of journals and books are to be spelled out in full (except JAMA) and italicized. Sample references in the style of the ICMJE Uniform Requirements for Manuscripts Submitted to Biomedical Journals can be obtained at http:/ / www.nlm.nih.gov/bsd/uniform_requirements.html. Lawyers may use their own standard style ("The Bluebook") but avoid abbreviations.

Examples of the correct CQ format follow.

1. Parker SG, Kassirer JP. Decision analysis. New England Journal of Medicine 1987;316:250-8. or: . . 1987;316(2):250-8.

2. Beauchamp TL, Walters L, eds. Contemporary Issues in Bioethics, 4th ed. Belmont, CA: Wadsworth; 1994.

3. Weinstein L, Swartz MN. Pathogenic properties of invading microorganisms. In: Sodeman WA Jr, Sodeman WA, eds. Pathologic Physiology: Mechanisms of Disease. Philadelphia: WB Saunders; 1974:457-72.

4. See note 2, Beauchamp, Walters 1994:431-512.

5. Mathewes-Green F. Dignity, always dignity. World Magazine 1995 Feb 18; available at http://www.theologymatters.com/TMIssues/Mayjun97.pdf (last accessed 15 Jul 2007).

"Unpublished observations" and "personal communications" should not appear in the references, but should be inserted in parentheses in the text.

Quotations: Extensive quotations should be set off in a separate paragraph with double indentation. Short quotations remain in the running text, enclosed in double quotation marks. When quoting another author, always indicate the specific source page number in the corresponding endnote.

Abbreviations: Avoid abbreviations in the title. The full term for which an abbreviation stands should precede its first use in the text.

MANUSCRIPT SUBMISSION. Manuscript submissions should be sent to Thomasine Kushner, Ph.D. To facilitate review, manuscripts are to be submitted as electronic copy, preferably in MS Word, and addressed to: kushnertk@gmail.com. Before manuscripts can be considered for review, they must meet the standard requirements of written academic English. Author(s) should state, in a covering letter, that the material has not been previously published elsewhere nor submitted for publication elsewhere. Authors should also disclose financial or other relationships that might lead to a conflict of interest.

COPYRIGHT. Authors of accepted articles will be asked to sign a Transfer of Copyright form, transferring copyright of the article to the publisher. 
Bioethics in Denmark: Moving from First- to Second-Order Analysis?

Morten Ebbe JuUl Nielsen and Martin Marchman Andersen

Documentation of Capacity and Identification of Substitute Decisionmakers in Ontario

Thomas C. Foreman, Dorothyann Curran, Joshua T. LANDry, AND Michael A. KeKewich

Hospice and Palliation in the English-Speaking Caribbean

Cheryl Cox Macpherson, Nina Chiochankitmun, and Muge AKrinar-Elci

Interactions between Doctors and Pharmaceutical Sales Representatives in a Former Communist Country: The Ethical Issues

Marta MaKowsKa

Informed Consent in Croatia: A Work in Progress

LUKA VuČEMILO AND ANA BOROVEČKI

\section{Departments and Columns}

\section{Neuroethics Now}

Beyond Consent in Research: Revisiting Vulnerability in Deep Brain Stimulation for Psychiatric Disorders

Emily Bell, Eric Racine, Paula Chiasson, Maya Dufource-Brana, Laura B. Dunn, Joseph J. Fins, Paul J. Ford, Walter Glannon, Nir Lipsman, Mary Ellen Macdonald,

Debra J. H. Mathews, and Mary Pat McAndrews

Best Practices Guidelines for Publishing in the Bioethics Literature 


\section{CONTENTS}

\section{Cambridge \\ Quarterly of}

Healthcare

\section{Ethics}

A Quarterly

Journal Devoted

to Engaging a

World Community

of Bioethicists

\section{VOLUME 23}

NUMBER 3

JULY 2014
Contributors

Editorial: Military Medical Torture and Denial, Redux

Steve Heilig

\section{Breaking Bioethics}

". . . How Narrow the Strait!" The God Machine and the Spirit of Liberty

JOHN HARRIS

\section{Special Section: Bioethics beyond Borders}

Medical Ethics and New Public Management in Sweden Sven Ove Hansson

An Unfortunate Experiment? The Future of Ethical Review in New Zealand

JoHn McMillan AND LyNne Bowyer

China's One-Child Policy, a Policy without a Future: Pitfalls of the "Common Good" Argument and the Authoritarian Model

JING-BAO NIE

Governance of Biomedical Research in Singapore and the Challenge of Conflicts of Interest

Calvin Wai Loon Ho, Leonardo D. De Castro, and Alastair V. CAMpbell

Neuroethics in a "Psy" World: The Case of Argentina

ARLEEN SALles

Opt-Outs and Upgrades: Ethics and Law in the United Kingdom

Trevor Stammers and Matt James

Sex Definitions and Gender Practices: An Update from Australia

KATE CREgAN 